\title{
Statin therapy reduces the likelihood of suboptimal blood pressure control among Ugandan adult diabetic patients
}

This article was published in the following Dove Press journal:

Therapeutics and Clinical Risk Management

20 February 2017

Number of times this article has been viewed

\section{William Lumu' \\ Leaticia Kampiire ${ }^{2}$ \\ George Patrick Akabwai ${ }^{3}$ \\ Daniel Ssekikubo Kiggundu ${ }^{4}$ \\ Davis Kibirige ${ }^{5}$}

'Department of Medicine and Diabetes/Endocrine Unit, Mengo Hospital, ${ }^{2}$ Infectious Disease

Research Collaboration, ${ }^{3}$ Baylor College of Medicine Children's Foundation, ${ }^{4}$ Nephrology Unit, Mulago National Referral and Teaching Hospital, ${ }^{5}$ Department of Medicine, Uganda Martyrs Hospital Lubaga, Kampala, Uganda
Correspondence: Davis Kibirige Department of Medicine, Uganda Martyrs Hospital Lubaga, PO Box 7|46, Kampala, Uganda

Tel +2564 I 4267012

Email kibirigedavis@gmail.com
Background: Hypertension is one of the recognized risk factors of cardiovascular diseases in adult diabetic patients. High prevalence of suboptimal blood pressure (BP) control has been well documented in the majority of studies assessing BP control in diabetic patients in sub-Saharan Africa. In Uganda, there is a dearth of similar studies. This study evaluated the prevalence and correlates of suboptimal BP control in an adult diabetic population in Uganda. Patients and methods: This was a cross-sectional study that enrolled 425 eligible ambulatory adult diabetic patients attending three urban diabetic outpatient clinics over 11 months. Data about their sociodemographic characteristics and clinical history were collected using pre-tested questionnaires. Suboptimal BP control was defined according to the 2015 American Diabetes Association standards of diabetes care guideline as BP levels $\geq 140 / 90 \mathrm{mmHg}$.

Results: The mean age of the study participants was $52.2 \pm 14.4$ years, with the majority being females $(283,66.9 \%)$. Suboptimal BP control was documented in 192 (45.3\%) study participants and was independently associated with the study site (private hospitals; odds ratio $2.01,95 \%$ confidence interval 1.18-3.43, $P=0.01$ ) and use of statin therapy (odds ratio $0.5,95 \%$ confidence interval $0.26-0.96, P=0.037$ ).

Conclusion: Suboptimal BP control was highly prevalent in this study population. Strategies to improve optimal BP control, especially in the private hospitals, and the use of statin therapy should be encouraged in adult diabetic patients.

Keywords: suboptimal blood pressure control, statin therapy, diabetic, Uganda

\section{Introduction}

Globally, cardiovascular diseases (CVDs) are the leading causes of adult morbidity and mortality. In 2012, an estimated 17.5 million people died from CVDs, which represents $31 \%$ of all global deaths. Approximately $80 \%$ of these deaths are documented to occur in low- and middle-income countries. ${ }^{1}$ Hypertension (HT) is one of the documented traditional risk factors of CVDs. ${ }^{2}$ Diabetes mellitus (DM)-HT comorbidity is frequently encountered in clinical practice, especially among adult diabetic patients. ${ }^{3,4}$ Optimal control of both conditions is associated with delayed onset and progression of microvascular and macrovascular complications and related cardiovascular mortality., Despite several studies reporting the burden and predictors of suboptimal blood pressure (BP) control among African diabetic patients, similar studies are limited in Uganda. ${ }^{4,7}$ Hence, this study sought to examine the prevalence and correlates of suboptimal BP control in an adult diabetic population attending three urban outpatient diabetic clinics in Uganda. 


\section{Patients and methods}

This was a cross-sectional study performed from September 2014 to July 2015 at three urban outpatient diabetic clinics of Mulago National Referral and Teaching Hospital, a public hospital where health care services are offered at no charge, and at Mengo Hospital and Our lady of Consolata Hospital, Kisubi, which are not-for-profit faith-based hospitals where health services are offered to patients at lower costs. These three hospitals serve an urban population of $\sim 2$ million people.

The diabetes clinic is usually run once weekly in the morning for enrollment of new patients and follow-up of old registered patients. An average of 35 patients are reviewed on each clinic day by either a general practitioner or a specialist physician. At each visit, patients are offered diabetic education by an experienced diabetic educator or nurse that includes information about diabetes, its complications such as HT, nutrition, adherence to medications and self-monitoring. BP measurement is usually performed using either a digital BP machine or a mercury sphygmomanometer by a diabetes nurse after at least 15 minutes of rest. Anthropometric measurements of height and weight to calculate the body mass index (BMI) and measurement of the fasting blood sugar level using an early morning fasting capillary blood sample are also routinely done at each visit.

At each center, patients aged $\geq 18$ years with a confirmed diagnosis of diabetes by a general practitioner or a physician using fasting blood glucose levels, an oral glucose tolerance test, glycated hemoglobin $(\mathrm{HbA} 1 \mathrm{c})$ or random blood sugar level in the presence of symptoms of diabetes; patients who had been receiving care for at least a minimum of 6 months and patients who provided written informed consent were considered eligible and enrolled consecutively until the desired sample size was attained. Patients who were too sick to provide written informed consent were excluded from the study (Figure 1).

\section{Data collection}

Using a pre-tested questionnaire, information about the study participants' sociodemographic characteristics, preexisting medical conditions (coexisting HT and HIV), type of diabetes, age at diagnosis of DM, duration since diagnosis and drug history was collected.

After providing written informed consent, all study participants were subjected to a single BP measurement using a digital BP machine following a minimum of 15 minutes rest at the clinic. They also underwent standard weight and height measurements to calculate the BMI and measurement of HbA1c, low-density lipoprotein cholesterol (LDLC), highdensity lipoprotein cholesterol (HDLC), triglyceride and total cholesterol (TC) concentrations using a fasting venous blood. The analysis of the above blood tests was done at each center using a fully automated COBAS ${ }^{\circledR}$ INTEGRA 400 (Hoffman-La Roche Ltd., Basel, Switzerland) machine.

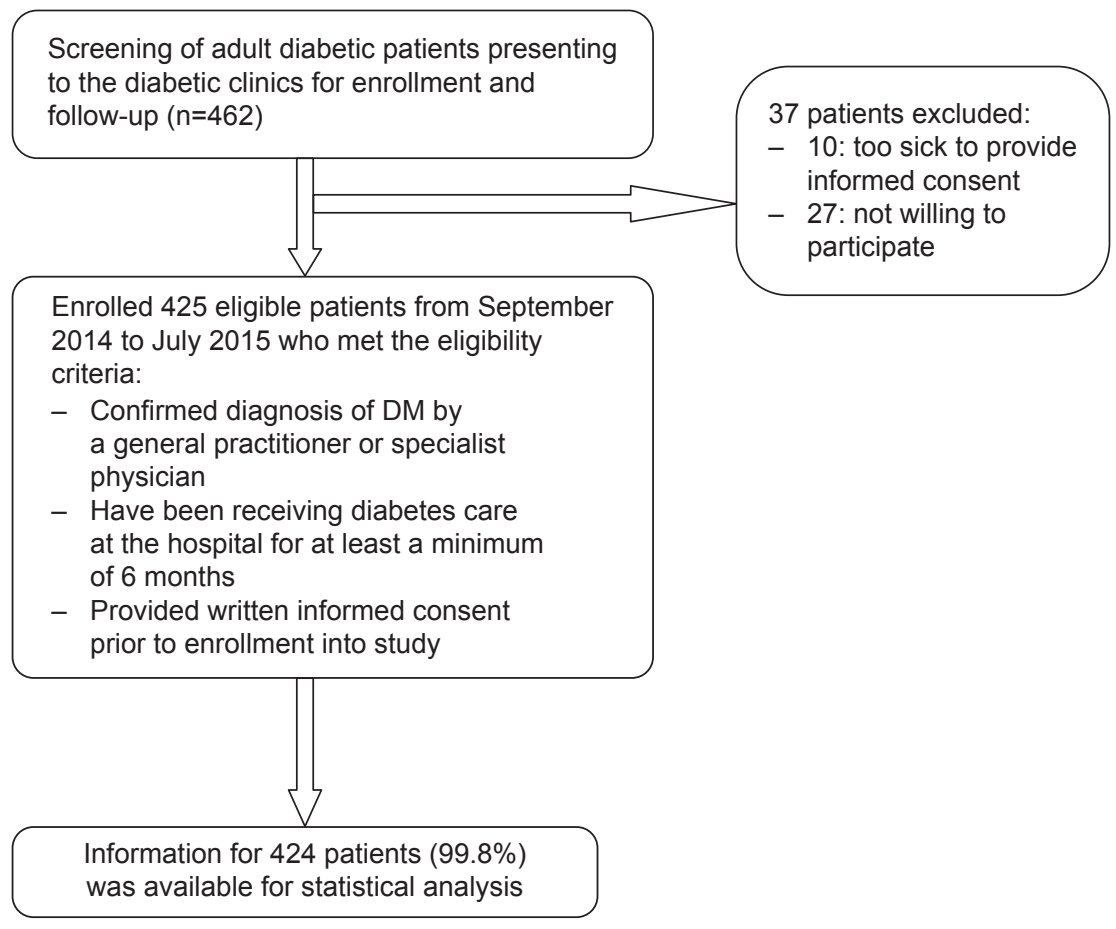

Figure I Flow chart of enrollment of study participants. Abbreviation: DM, diabetes mellitus. 


\section{Statistical analysis}

Data were entered into Microsoft Excel database, and Stata software (version 12.1) was used for all statistical analyses. Patient characteristics were reported as frequencies and percentages for categorical variables and median and interquartile range (IQR) values for continuous variables, which were not normally distributed.

The 2015 American Diabetes Association guideline of standards of diabetes care was used to define suboptimal BP control among adult diabetic patients as BP levels $\geq 140 / 90 \mathrm{mmHg}$, regardless of the patient category, ie, age, duration of disease or presence of concomitant comorbidities. ${ }^{8}$ We also defined normal or optimal BP and stage 1 and stage 2 HT as BP $<140 / 90 \mathrm{mmHg}$, BP $=140$ 159/90-99 mmHg and BP $\geq 160 / 100 \mathrm{mmHg}$, respectively.

To determine the associations between the different sociodemographic, clinical and laboratory factors and suboptimal BP control, bivariate analyses using chi-square test were performed. Multivariate analysis was performed using logistic regression to identify the independent predictors of suboptimal BP control. The model was built in a stepwise manner by initially putting all variables with $P$-values $<0.2$ in the bivariate analysis and reducing the model starting with those that did not lower the Akaike information criterion. Variables that were biologically plausible were also included in the final model. A $P$-value of $<0.05$ and confidence intervals (CIs) not including 1 were considered to be statistically significant.

\section{Ethics approval}

This study was approved by the ethical review boards of Makerere University College of Health Sciences, Mengo Hospital and Our Lady of Consolata Hospital, Kisubi.

\section{Results}

\section{Sociodemographic and clinical characteristics of the study participants}

The median (IQR) age of the study participants was 53 years (43.5-62 years). The majority of the participants were females $(284,66.98 \%)$ and had primary or lower level of education $(165,38.92 \%)$. Family history of DM and HT comorbidity was documented in $62.26 \%$ and $68.87 \%$ of the study participants, respectively. All patients with coexisting HT were on BP-lowering treatment with either an angiotensin-converting enzyme inhibitor or angiotensin II receptor blocker component. Insulin therapy, oral glucoselowering agents and statin therapy were used in $44.34 \%$, $55.7 \%$ and $20.94 \%$ of the study participants, respectively (summarized in Table 1).
Table I Sociodemographic, clinical and laboratory characteristics of the study participants

\begin{tabular}{|c|c|}
\hline Variable & Values \\
\hline Age (years), median (IQR) & $53(43.5-62)$ \\
\hline \multicolumn{2}{|l|}{ Gender, n (\%) } \\
\hline Male & $140(33.02)$ \\
\hline Female & $284(66.98)$ \\
\hline \multicolumn{2}{|l|}{ Education level, n (\%) } \\
\hline None & $38(8.96)$ \\
\hline Primary & $165(38.92)$ \\
\hline Secondary & $14 \mid(33.25)$ \\
\hline Tertiary & $79(18.63)$ \\
\hline \multicolumn{2}{|l|}{ Occupation, n (\%) } \\
\hline Employed & $212(50)$ \\
\hline Unemployed & $212(50)$ \\
\hline \multicolumn{2}{|l|}{ Marital status, n (\%) } \\
\hline Married & $259(61.08)$ \\
\hline Cohabiting & $10(2.36)$ \\
\hline Single & 47 (II.08) \\
\hline Divorced & $4 \mathrm{I}(9.67)$ \\
\hline Widow/widowed & $67(15.80)$ \\
\hline \multicolumn{2}{|l|}{ Place of residence, $n(\%)$} \\
\hline Rural & $136(32.08)$ \\
\hline Urban & $288(67.92)$ \\
\hline \multicolumn{2}{|l|}{ Study site, n (\%) } \\
\hline Government & $199(46.82)$ \\
\hline Private & $226(53.18)$ \\
\hline \multicolumn{2}{|l|}{ Smoking, n (\%) } \\
\hline Yes & $10(2.35)$ \\
\hline No & $415(97.65)$ \\
\hline \multicolumn{2}{|l|}{ Known HT, n (\%) } \\
\hline Yes & $292(68.87)$ \\
\hline No & $132(31.13)$ \\
\hline \multicolumn{2}{|l|}{ HIV coexistent, n (\%) } \\
\hline Yes & $17(4.00)$ \\
\hline No & $408(96.00)$ \\
\hline \multicolumn{2}{|l|}{ Family history of DM, $n$ (\%) } \\
\hline Yes & $264(62.26)$ \\
\hline No & $160(37.74)$ \\
\hline \multicolumn{2}{|l|}{ Type of DM, n (\%) } \\
\hline Type I DM & $55(13.13)$ \\
\hline Type 2 DM & $364(86.87)$ \\
\hline \multicolumn{2}{|l|}{ Drug history, n (\%) } \\
\hline Diet alone & $3(0.7 \mathrm{I})$ \\
\hline Met alone & 79 (I8.59) \\
\hline Met + SU & $127(29.88)$ \\
\hline$M e t+S U+T Z D$ & $16(3.76)$ \\
\hline Met + incretin & $8(1.88)$ \\
\hline Insulin alone/+ Met & $188(44.34)$ \\
\hline \multirow[t]{2}{*}{ Statins } & $89(20.94)$ \\
\hline & Median (IQR), N=425 \\
\hline Age at diagnosis (years) & $47(37-55)$ \\
\hline Duration with DM (years) & $4.5(2-10)$ \\
\hline $\mathrm{BMI}\left(\mathrm{kg} / \mathrm{m}^{2}\right)$ & $27(23-30.6)$ \\
\hline $\mathrm{HbAIc}(\%)$ & $9(6.8-12.4)$ \\
\hline LDLC (mmol/L) & $2.9(2.3-3.84)$ \\
\hline $\mathrm{HDLC}(\mathrm{mmol} / \mathrm{L})$ & $1.19(0.9-1.42)$ \\
\hline $\mathrm{TC}(\mathrm{mmol} / \mathrm{L})$ & $4.82(4 . \mid-5.7 I)$ \\
\hline TGL (mmol/L) & $1.6(1.23-2.2)$ \\
\hline $\mathrm{SBP}(\mathrm{mmHg})$ & $139(124-155)$ \\
\hline $\mathrm{DBP}(\mathrm{mmHg})$ & $80(73-9 \mid)$ \\
\hline
\end{tabular}

Note: Copyright @20 I7. Dove Medical Press. Reproduced from Kibirige D, Akabwai GP, Kampiire L, Kiggundu DS, Lumu W. Frequency and predictors of suboptimal glycemic control in an African diabetic population. Int J Gen Med. In press 2017.17 Abbreviations: IQR, interquartile range; $\mathrm{HT}$, hypertension; DM, diabetes mellitus; Met, metformin; SU, sulfonylurea; BMI, body mass index; HbAlc, glycated hemoglobin; LDLC, low-density lipoprotein cholesterol; HDLC, high-density lipoprotein cholesterol; TC, total cholesterol; TGL, triglyceride; TZD, thiazolidinedione; SBP, systolic blood pressure; DBP, diastolic blood pressure. 


\section{Status of BP control}

The median systolic BP (SBP) and diastolic BP (DBP) were $139 \mathrm{mmHg}(124-155 \mathrm{mmHg}$ ) and $80 \mathrm{mmHg}(73-91 \mathrm{mmHg}$ ), respectively. Suboptimal BP control was noted in 192 study participants, giving a prevalence of $45.3 \%$. Of these participants with suboptimal BP control, 91 (21.41\%) and 101 $(23.76 \%)$ had stage 1 and stage $2 \mathrm{HT}$, respectively. None of the participants with DM-HT comorbidity had optimal BP control of $<140 / 90 \mathrm{mmHg}$.

\section{Sociodemographic, clinical and laboratory characteristics of the study participants at bivariate analysis}

At bivariate analysis, age in completed years $(P=0.019)$, gender $(P=0.032)$, study site $(P=0.007)$, type of diabetes ( $P=0.164)$, median age at diagnosis $(P=0.025)$, median years with diabetes $(P=0.126)$, BMI $(P=0.040)$, metformin (Met) and sulfonylurea (SU; $P=0.071$ ), incretin and Met combination $(P=0.097)$, Met, SU and thiazolidinedione (TZD) combination $(P=0.167)$, insulin therapy $(P=0.073)$, statin therapy ( $P=0.081)$, LDLC levels $(P=0.077)$, HDLC levels $(P=0.108)$, TC levels $(P=0.042)$ and non-HDLC $(P=0.071)$ were considered. Table 2 summarizes the sociodemographic, clinical and laboratory characteristics of the study participants in association with suboptimal BP control at bivariate analysis.

\section{Independent predictors of suboptimal BP control at multivariate analysis}

At multivariate analysis, the only independent predictors of suboptimal BP control were type of study site (private hospitals; adjusted odds ratio $2.01,95 \%$ CI $1.18-3.43, P=0.010$ ) and use of statin therapy (adjusted odds ratio 0.50, 95\% CI 0.26-0.96, $P=0.037$; shown in Table 3).

\section{Discussion}

This cross-sectional study demonstrates a high prevalence of suboptimal BP control in this study population, accounting for $\sim 5$ in 10 adult diabetic patients. Patients seeking diabetes care from a private hospital were twice more likely to have suboptimal BP control compared to those attending the government hospital. The use of statin therapy reduced the likelihood of suboptimal BP control by $50 \%$.

High prevalence of suboptimal BP control has been reported in African diabetic patients in several studies. ${ }^{4,7,9-11}$ In the largest study to assess the quality of diabetes care performed among adult diabetic patients in sub-Saharan Africa to date, the Diabcare Africa study, suboptimal BP control was documented in $79 \%$ of the 2,352 study participants. ${ }^{4}$ Other similar smaller studies conducted in Uganda, Ethiopia and South Africa have reported prevalence between $44 \%$ and $68 \% .^{7,9-11}$

In comparison to our study, the wide disparity in the documented prevalence could be explained by varying study definitions of suboptimal BP control. Most of the above studies defined suboptimal BP control as BP $>130$ / $80 \mathrm{mmHg}, \mathrm{BP} \geq 140 / 80 \mathrm{mmHg}$ or $\mathrm{SBP} \geq 130 \mathrm{mmHg}$ and/ DBP $\geq 80 \mathrm{mmHg}$.

\section{Independent predictors of suboptimal $\mathrm{BP}$ control}

Seeking diabetes care from private hospitals and use of statin therapy were independently associated with suboptimal BP control. The probable reason to explain the increased likelihood of suboptimal BP control among patients receiving diabetes care from private hospitals is the high cost of antihypertensive drugs. This directly affects access to these drugs and adherence, resulting into suboptimal BP control. In Uganda, medical care in government hospitals is offered at no cost to the patients. Patients attending diabetes clinics in these hospitals are offered the prescribed antihypertensive drugs and glucose-lowering drugs free of charge if available in the hospital pharmacies.

The use of statin therapy reduced the likelihood of suboptimal BP control in this study population. To our knowledge, this correlation has not been demonstrated in any study in African diabetic patients. Some studies have shown that statins offer modest BP reductions, a clinical benefit that is independent of their recognized lipid-lowering properties. In one large cross-sectional study performed using data from the national health and nutritional survey in the USA, the effect of statins on BP was evaluated in 995 patients on statin treatment and 9,536 patients not on statins. ${ }^{12}$ They were stratified according to the history of use of antihypertensive drugs, BP and HDLC levels. Statin therapy decreased SBP by $3.3 \mathrm{mmHg}$ among patients on antihypertensive medication (interaction $P<0.02$ ); reduced DBP by an average of $1.9 \mathrm{mmHg}(P<0.01)$, regardless of antihypertensive medication use, and in patients with low HDLC ( $\leq 49 \mathrm{mmHg}$ ), reduced DBP by $3.4 \mathrm{mmHg}$. Among patients on antihypertensive medications, statin users had a lower mean SBP of $4 \mathrm{mmHg}$ compared to the statin nonusers. This study concluded that statin therapy contributes to optimal BP control in hypertensive patients and in patients with low HDLC levels. In our study, $68.9 \%$ and $29.2 \%$ of the study participants had HT comorbidity and low HDLC levels (defined as levels $<40 \mathrm{mg} / \mathrm{dL}$ ). 
Table 2 Bivariate analysis of sociodemographic and clinical characteristics associated with suboptimal BP control

\begin{tabular}{|c|c|c|c|c|}
\hline Characteristics & $B P \geq 140 / 90 \mathrm{mmHg}$ & $\mathrm{BP}<140 / 90 \mathrm{mmHg}$ & OR (95\% Cl) & $P$-value \\
\hline Age (years), mean (SD) & $53.98(0.99)$ & $50.67(0.97)$ & $1.02(1.00-1.03)$ & 0.019 \\
\hline \multicolumn{5}{|l|}{ Gender, n (\%) } \\
\hline Male & $139(72.40)$ & $87(37.50)$ & 1 & \\
\hline Female & $53(27.60)$ & $145(62.50)$ & $0.64(0.420-0.961)$ & 0.032 \\
\hline \multicolumn{5}{|l|}{ Type of hospital, n (\%) } \\
\hline Government & $88(45.83)$ & $137(59.05)$ & 1 & \\
\hline Private & $104(54.17)$ & $95(40.95)$ & 1.70 (I.I58-2.507) & 0.007 \\
\hline \multicolumn{5}{|l|}{ Place of residence, n (\%) } \\
\hline Rural & $125(65.10)$ & $163(70.26)$ & 1 & \\
\hline Urban & $67(34.90)$ & $69(29.74)$ & $1.27(0.84 \mid-1.906)$ & 0.258 \\
\hline \multicolumn{5}{|l|}{ Smoking, n (\%) } \\
\hline Smoker & $3(1.56)$ & $7(3.02)$ & 1 & \\
\hline Non-smoker & I 89 (98.44) & $225(96.98)$ & $0.51(0.130-2.000)$ & 0.334 \\
\hline \multicolumn{5}{|l|}{ Occupation, n (\%) } \\
\hline Employed & $92(47.92)$ & $120(5 \mid .72)$ & 1 & \\
\hline Unemployed & $100(52.08)$ & II 2 (48.28) & $0.86(0.586-1.26)$ & 0.435 \\
\hline \multicolumn{5}{|l|}{ DM type, n (\%) } \\
\hline Type 2 DM & $169(89.42)$ & $195(84.78)$ & 1 & \\
\hline Type I DM & $20(10.58)$ & 35 (I5.22) & $0.66(0.367-1.186)$ & 0.164 \\
\hline \multicolumn{5}{|l|}{ Family history of DM, n (\%) } \\
\hline Yes & $|2|(63.02)$ & $143(6 \mid .64)$ & 1 & \\
\hline No & 71 (36.98) & $89(38.36)$ & $1.06(0.7 \mid 5-1.574)$ & 0.770 \\
\hline \multicolumn{5}{|l|}{ HIV comorbidity, n (\%) } \\
\hline Yes & $8(4.17)$ & $9(3.88)$ & 1 & \\
\hline No & $184(95.83)$ & $223(96.12)$ & $\mathrm{I} .08(0.407-2.848)$ & 0.881 \\
\hline Median age (years) at diagnosis, $\mathrm{n}(\%)$ & $47.49(12.74)$ & $44.60(13.39)$ & $1.02(1.00-1.03)$ & 0.025 \\
\hline Median years with DM, n (\%) & $7.34(6.53)$ & $6.40(6.07)$ & $1.02(0.99-1.06)$ & 0.126 \\
\hline BMI $\left(\mathrm{kg} / \mathrm{m}^{2}\right), \mathrm{n}(\%)$ & $28.03(5.98)$ & $26.76(6.28)$ & $1.03(1.00-1.07)$ & 0.040 \\
\hline \multicolumn{5}{|l|}{ Glucose lowering therapy, n (\%) } \\
\hline Met alone & $38(48.10)$ & $4 \mid(51.90)$ & I.I5 (0.704-I.876) & 0.577 \\
\hline Met + SU & $66(51.97)$ & 61 (48.03) & $1.47(0.967-2.229)$ & 0.071 \\
\hline Incretin** + Met & $\mathrm{I}(12.50)$ & $7(87.50)$ & $0.17(0.205-1.380)$ & 0.097 \\
\hline Met + SU + TZD & $10(62.50)$ & $6(37.50)$ & $2.07(0.738-5.802)$ & 0.167 \\
\hline Insulin alone/+ Met & $76(40.43)$ & $112(59.72)$ & $0.70(0.477-1.034)$ & 0.073 \\
\hline \multicolumn{5}{|l|}{ On statin therapy, n (\%) } \\
\hline No & $159(47.46)$ & $176(52.54)$ & 1 & \\
\hline Yes & $33(37.08)$ & $56(62.92)$ & $1.53(0.95-2.48)$ & 0.081 \\
\hline LDLC, median (IQR) & $2.97(2.4-3.86)$ & $2.88(2.22-3.8)$ & $1.16(0.98-1.37)$ & 0.077 \\
\hline HDLC, median (IQR) & $1.2(0.96-1.5)$ & $1.16(0.9-1.4)$ & $\mathrm{I} .43(0.92-2.22)$ & 0.108 \\
\hline TC, median (IQR) & $5(4.24-5.89)$ & $4.74(4-5.65)$ & $1.17(1.00-1.36)$ & 0.042 \\
\hline TGL, median (IQR) & $1.66(1.28-2.15)$ & $1.54(1.19-2.24)$ & $0.96(0.79-1.15)$ & 0.632 \\
\hline Non-HDLC, median (IQR) & $3.59(2.8-4.5)$ & $3.67(3.02-4.69)$ & $1.16(0.99-1.37)$ & 0.071 \\
\hline TC/HDLC ratio, median (IQR) & $4.14(3.3-5.4)$ & $4.2(3.3-5.2)$ & $0.98(0.90-1.07)$ & 0.717 \\
\hline
\end{tabular}

Note: **All the patients were on a saxagliptin.

Abbreviations: BP, blood pressure; OR, odds ratio; Cl, confidence interval; BMI, body mass index; DM, diabetes mellitus; Met, metformin; SU, sulfonylurea; TZD, thiazolidione; LDLC, low-density lipoprotein cholesterol; IQR, interquartile range; HDLC, high-density lipoprotein cholesterol; TC, total cholesterol; TGL, triglyceride.

The effect of BP lowering due to statin therapy was also demonstrated in the University of California, San Diego Statin Study. This was a randomized, double-blind, placebo-controlled trial in which 973 men and women without known CVD or DM were equally randomized to simvastatin $20 \mathrm{mg}$, pravastatin sodium $40 \mathrm{mg}$ and placebo for 6 months. ${ }^{13}$ The study demonstrated that statins modestly but significantly reduced BP relative to placebo, by $2.2 \mathrm{mmHg}$ for SBP $(P=0.02)$ and $2.4 \mathrm{mmHg}$ for DBP $(P<0.001)$.

This statin-related BP-lowering effect and other additional beneficial effects that are independent of the lipid-lowering properties are called pleiotropic effects. Experimental observations have shown that statins have cellular anti-inflammatory, anti-proliferative and immunomodulatory effects, cause plaque stabilization, prevent platelet aggregation through 
Table 3 Independent predictors of suboptimal BP control on multivariate analysis

\begin{tabular}{|c|c|c|c|c|}
\hline \multirow[t]{2}{*}{ Variables } & \multicolumn{2}{|l|}{ Unadjusted } & \multicolumn{2}{|c|}{ Adjusted analysis } \\
\hline & OR $(95 \% \mathrm{Cl})$ & $P$-value & OR $(95 \% \mathrm{Cl})$ & $P$-value \\
\hline Study site & $1.70(|| 6-.2.5 I)$ & 0.007 & $2.01(1.18-3.43)$ & 0.010 \\
\hline BMI $\left(\mathrm{kg} / \mathrm{m}^{2}\right)$ & $1.03(1.00-1.07)$ & 0.040 & $1.03(0.99-1.07)$ & 0.157 \\
\hline Type of DM & $0.66(0.37-1.19)$ & 0.164 & $1.76(0.67-4.59)$ & 0.251 \\
\hline LDLC & $1.16(0.98-1.37)$ & 0.077 & $1.05(0.86-1.29)$ & 0.619 \\
\hline Age, years & $1.02(1.00-1.03)$ & 0.019 & $1.01(0.98-1.04)$ & 0.438 \\
\hline $\begin{array}{l}\text { Age at } \\
\text { diagnosis, years }\end{array}$ & $1.02(1.00-1.03)$ & 0.025 & 1.01 (0.98-1.04) & 0.586 \\
\hline Met and SU & I.47 (0.97-2.23) & 0.071 & $1.36(0.80-2.29)$ & 0.254 \\
\hline Met-SU-TZD & $2.07(0.74-5.80)$ & 0.167 & $2.59(0.73-9.17)$ & 0.139 \\
\hline $\begin{array}{l}\text { On statin } \\
\text { therapy }\end{array}$ & $1.53(0.95-2.48)$ & 0.081 & $0.50(0.26-0.96)$ & 0.037 \\
\hline
\end{tabular}

Abbreviations: $\mathrm{BP}$, blood pressure; $\mathrm{OR}$, odds ratio; $\mathrm{Cl}$, confidence interval; $\mathrm{BMI}$, body mass index; DM, diabetes mellitus; LDLC, low-density lipoprotein cholesterol; Met, metformin; SU, sulfonylurea;TZD, thiazolidione.

their inhibition effect on thromboxane A2, improve endothelial nitric oxide (NO) bioavailability and reduce cellular oxidative stress. $^{14-16}$

The pleiotropic effect of BP lowering by statins is explained by several mechanisms. Statins induce increased expression of endothelial NO synthase, which increases bioavailability of NO, a potent vasodilator and inhibitor of vascular thrombosis and inflammation. Statins also have demonstrated cellular anti-oxidative properties, which limit vascular damage. This is because of their effect of preventing isoprenylation of the GTP-binding protein $\mathrm{p} 21 \mathrm{Rac}$, which reduces production of nicotinamide adenine dinucleotide phosphate oxidase and reactive oxygen species in endothelial cells, which would scavenge the vasodilating NO. Statins also induce increased production of thrombomodulin and tissue plasminogen activator and inhibit vascular smooth muscle cell proliferation, expression of vascular cell adhesion molecules such as VCAM-1 and sICAM-1, expression of angiotensin I receptor and angiotensin II-dependent intracellular signaling and synthesis of angiotensin II and aldosterone. ${ }^{14-16}$ These multiple effects are integral in maintaining normal vasomotor tone and hemostatic balance.

\section{Study limitations}

Because of the nature of the study (cross-sectional study performed in three urban hospitals), we cannot generalize to the entire adult diabetic population seeking care in Uganda. A single BP reading was used, which might affect the results obtained. Despite these limitations, this is the first large multicenter study to examine the prevalence of suboptimal BP control and its predictors in adult diabetic patients in Uganda.

\section{Conclusion and recommendations}

Suboptimal BP control was relatively common in this study population. Approaches to improve BP control should be emphasized among diabetic patients seeking care from private hospitals. Routine use of statins should be encouraged in patients with DM-HT comorbidity to maintain optimal BP control. In-depth qualitative studies to identify causes of suboptimal BP control in adult diabetic patients should be undertaken to assist in offering practical solutions and guide policy formulation and implementation.

\section{Acknowledgment}

We would like to recognize and thank all the study participants who participated in this study and the entire research team, especially the nursing staff at the respective study sites who assisted in patient identification and enrollment.

\section{Disclosure}

DK works in the medical unit of GlaxoSmithKline (GSK) in Uganda. None of the described work was funded by GSK, and the views expressed here are solely of the authors. The other authors report no conflicts of interest in this work.

\section{References}

1. WHO-Cardiovascular Diseases. 2016. Available from: http://www. who.int/mediacentre/factsheets/fs317/en/. Accessed June 6, 2016.

2. Lim S, Vos T, Flaxman A, et al. A comparative risk assessment of burden of disease and injury attributable to 67 risk factors and risk factor clusters in 21 regions, 1990-2010: a systematic analysis for the Global Burden of Disease Study 2010. Lancet. 2012;380(9859):2224-2260.

3. Chan J, Gagliardino J, Baik S, et al. Multifaceted determinants for achieving glycemic control-the international diabetes management practice study (IDMPS). Diabetes Care. 2009;32(2):227-233.

4. Sobngwi E, Ndour-Mbaye M, Boateng K, et al. Type 2 diabetes control and complications in specialised diabetes care centres of six sub-Saharan African countries: the Diabcare Africa study. Diabetes Res Clin Pract. 2012;95(1):30-36.

5. Stratton I, Adler A, Neil H, et al. Association of glycaemia with macrovascular and microvascular complications of type 2 diabetes (UKPDS 35): prospective observational study. BMJ. 2000;321(7258):405-412.

6. Holman R, Paul S, Bethel M, Neil H, Matthews D. Long-term follow-up after tight control of blood pressure in type 2 diabetes. $N$ Engl J Med. 2008;359(15):1565-1576.

7. Webb E, Rheeder P, Van Zyl D. Diabetes care and complications in primary care in the Tshwane district of South Africa. Prim Care Diabetes. 2015;9(2):147-154.

8. American-Diabetes-Association. Cardiovascular disease and risk management. Diabetes Care. 2015;38(suppl 1):S49-S57.

9. Gudina E, Amade S, Tesfamichael F, Ram R. Assessment of quality of care given to diabetic patients at Jimma University Specialized Hospital diabetes follow-up clinic, Jimma, Ethiopia. BMC Endocr Disord. 2011;11:19

10. Mekong J, Kengne A, Dehayem M, Sobngwi E, Mbanya J. Cardiovascular preventative therapies and outcomes of care among urban sub-Saharan Africans with type 2 diabetes: a cross-sectional study in Cameroon. J Clin Outcomes Manage. 2012;19(10):446-452. 
11. Kibirige D, Atuhe D, Sebunya R, Mwebaze R. Suboptimal glycaemic and blood pressure control and screening for diabetic complications in adult ambulatory diabetic patients in Uganda: a retrospective study from a developing country. J Diabetes Metab Disord. 2014;13(1):40.

12. Bautista L. Blood pressure-lowering effects of statins: who benefits? J Hypertens. 2009;27(7):1478-1484.

13. Golomb B, Dimsdale J, White H, Ritchie J, Criqui M. Reduction in blood pressure with statins. Results from the UCSD statin study, a randomized trial. Arch Intern Med. 2008;168(7):721-727.

14. Jain M, Ridker P. Anti-inflammatory effects of statins: clinical evidence and basic mechanisms. Nat Rev Drug Discov. 2005;4(12):977-987.
15. Drapala A, Sikora M, Ufnal M. Statins, the renin-angiotensin-aldosterone system and hypertension - a tale of another beneficial effect of statins. J Renin Angiotensin Aldosterone Syst. 2014;15(3):250-258.

16. Chopra V, Choksi P, Cavusoglu E. Beyond lipid lowering: the anti-hypertensive role of statins. Cardiovasc Drugs Ther. 2007;21(3): $161-169$.

17. Kibirige D, Akabwai GP, Kampiire L, Kiggundu DS, Lumu W. Frequency and predictors of suboptimal glycemic control in an African diabetic population. Int J Gen Med. In press 2017.

\section{Publish your work in this journal}

Therapeutics and Clinical Risk Management is an international, peerreviewed journal of clinical therapeutics and risk management, focusing on concise rapid reporting of clinical studies in all therapeutic areas outcomes, safety, and programs for the effective, safe, and sustained use of medicines. This journal is indexed on PubMed Central, CAS,
EMBase, Scopus and the Elsevier Bibliographic databases. The manuscript management system is completely online and includes a very quick and fair peer-review system, which is all easy to use. Visit http://www.dovepress.com/testimonials.php to read real quotes from published authors.

Submit your manuscript here: http://www.dovepress.com/therapeutics-and-clinical-risk-management-journal 